\title{
Invasive pneumococcal infections in Vellore, India: clinical characteristics and distribution of serotypes
}

Viktor Molander ${ }^{1 * \dagger}$, Camilla Elisson ${ }^{1 \dagger}$, Veeraraghavan Balaji ${ }^{2}$, Erik Backhaus ${ }^{3}$, James John $^{2}$, Rosemol Vargheese ${ }^{2}$, Ranjith Jayaraman ${ }^{2}$ and Rune Andersson ${ }^{1}$

\begin{abstract}
Background: Streptococcus pneumoniae infection is a serious problem worldwide and the case fatality rate remains high. The aim of this study was to analyze the distribution of pneumococcal serotypes causing invasive pneumococcal disease (IPD), to survey the potential coverage of present and future vaccines, and to investigate differences between serotypes and groups of serotypes with regard to manifestation, case fatality rate, age, and other risk factors.

Methods: Isolates from 244 consecutive patients with IPD were collected at the Christian Medical College, Vellore, India between January 2007 and June 2011, and clinical data were obtained retrospectively. Clinical characteristics were analyzed both for individual serotypes and for those grouped as "invasive", "pediatric", or "vaccine" serotypes.

Results: The serotype coverage for the pneumococcal conjugated vaccines (PCV) PCV7, PCV10, PCV13, PCV15, and pneumococcal polysaccharide vaccine (PPV) PPV23 was 29\%, 53\%,64\%, 66\%, and 73\%, respectively. The proportion of IPD caused by vaccine types was lower than pre-vaccination studies from other parts of the world. In adults, serotype 1 was mainly isolated from previously healthy patients without risk factors for IPD. This serotype caused more pneumonia and less meningitis than other serotypes, as was also noted for the "invasive" serotypes $(1,5$, and $7 \mathrm{~F})$.

Conclusions: The most common pneumococcal serotypes in this study behaved in similar ways to those in countries where the PCV has been introduced. Also, the most common serotypes in this study are included in the new PCVs. Therefore, a national program of childhood immunization with PCV10/13 in India is likely to be successful.
\end{abstract}

Keywords: Invasive pneumococcal disease, Pneumococcus, Vaccination, Pneumococcal vaccine, India, Serotype

\section{Background}

Streptococcus pneumoniae infection is a serious problem worldwide [1,2]. It is a common cause of pneumonia, meningitis, and septicemia, and the case fatality rate remains high [3]. Globally, India has the highest number of deaths caused by pneumococcal infections among children below 5 years of age, partly because of its large population [2]. The incidence, severity, and mortality of

\footnotetext{
* Correspondence: viktormolander@hotmail.com

${ }^{\dagger}$ Equal contributors

'Institute of Biomedicine, Department of Infectious Diseases, Sahlgrenska Academy, University of Gothenburg, Guldhedsgatan 10 A, P.O. Box 7193, 40234, Gothenburg, Sweden

Full list of author information is available at the end of the article
}

the disease depend on host factors such as age, underlying disease, comorbid conditions, and immunosuppression, but also on the properties of the organism [4]. Pneumococci are divided into different serotypes based on various properties of the capsule, and 94 different serotypes have been identified so far. The serotypes have varying abilities to cause invasive disease, and some serotypes tend to infect certain risk groups, such as children or patients with underlying diseases [4-6]. The serotype distribution varies over time and with geographic location, and local surveillance is therefore needed to determine the regional spread [7].

\section{Biomed Central}

(C) 2013 Molander et al.; licensee BioMed Central Ltd. This is an open access article distributed under the terms of the Creative Commons Attribution License (http://creativecommons.org/licenses/by/2.0), which permits unrestricted use, distribution, and reproduction in any medium, provided the original work is properly cited. 
Existing vaccines target the pneumococcal capsule and are serotype specific. The first immunogenic pneumococcal vaccine in children under the age of 2 years was the sevenvalent pneumococcal conjugate vaccine (PCV7), launched in 2000. Today, three PCVs, which include 7, 10, and 13 serotypes, have reached the market, and a PCV15 is under clinical trial [8]. The introduction of $\mathrm{PCV}$ has led to a marked decline in the incidence of vaccine type-IPD in both vaccinated children and unvaccinated adults in several countries [9]. Unfortunately, an increase in the incidence of IPD caused by non-vaccine serotypes following vaccination is a concern, especially the emergence of a serotype 19A clone with a high case fatality rate and multi-drug resistance [10]. To be able to estimate the efficacy prior to starting immunization in an area, it is important to investigate the disease burden, risk factors for disease, and serotype distribution [7]. Thus, more studies in India regarding these topics are needed.

The aim of this study was to analyze the distribution of pneumococcal serotypes causing IPD, to survey the potential coverage of present and future PCVs, and to investigate differences between serotypes and groups of serotypes with regard to manifestation, case fatality rate, age, and other risk factors.

\section{Methods}

\section{Study design}

Invasive pneumococcal isolates were collected consecutively at the Christian Medical College and Hospital (CMC) in Vellore, India, between January 2007 and June 2011 as part of an international surveillance program. CMC Vellore is a tertiary care multispecialty hospital that caters to 2500 inpatients and 6000 outpatients every day. It serves patients from all over India as well as neighboring countries, although citizens of Tamil Nadu State are overrepresented. The total number of blood cultures performed in 2012 was 35,658. Isolates were serotyped using a co-agglutination test [11] and confirmed by PCR [12]. Clinical data such as risk factors, manifestation, and outcome were collected retrospectively from February to April 2012 from hospital records. All samples were taken as part of the standard clinical care and the data were obtained from the ordinary patient records without any additional tests or visits for the patients. Antimicrobial susceptibility was determined using agar dilution to obtain minimal inhibitory concentration (MIC) in accordance with CLSI guidelines $[13,14]$. The revised breakpoints from January 2008 were used (parenteral cut-offs). If several isolates were extracted from the same patient, only one isolate from the same disease episode was included in the study. The study design and proposals were approved by the ethics committee and Institutional review board (IRB) of Christian Medical College, Vellore, South India.

\section{Definitions}

Invasive pneumococcal disease (IPD) was defined as isolation of pneumococci from normally sterile sites including blood, cerebral spinal fluid, pleural fluid, ascites, and synovial fluid. The local of infection was set by either positive cultivation or diagnosis by clinician. Case fatality was defined as death during the time of admission. Risk factors were defined as systemic autoimmune disease, cancer, cardiovascular disease, liver disease, kidney disease, lung disease, diabetes, HIV, other chronic conditions, splenectomy, previous skull fracture, immunosuppressive treatment, alcohol abuse, and smoking. Multi-drug resistance (MDR) was defined as resistant or intermediate resistant to $\geq 3$ antimicrobial agents.

When analyzing individual serotypes, all patients were divided into children ( $0-17$ years) and adults ( $\geq 18$ years). The pneumococcal serotypes were divided into "invasive serotypes" (1, 5, 7(A-C + F)), "pediatric serotypes" (6(A-C), 9(A, L, N , V), 14, 19(A-C + F), 23(A-B + F)), "PCV10" (1, 4, 5, 6B, 7 F, 9 V, 14, 18C, 19 F, 23 F) and "PCV13" (PCV10 serotypes $+3,6 \mathrm{~A}, 19 \mathrm{~A})$ serotypes, similar to other authors $[4,6,15]$.

\section{Statistical analysis}

The data were analyzed using SPSS (IBM, version 20) and Microsoft Excel (version 14.1.4). Fisher's exact test (two-sided) was used to calculate $\mathrm{p}$-values, and $\mathrm{p}<0.05$ was regarded as significant.

\section{Results}

Isolates from 244 patients with IPD were collected in this study. The ages ranged from 0-84 years, with a mean age of 29 years and median age of 28 years. There were 168 men and 76 women.

Risk factor data were available for 233 patients, of which 151 (62\%) had at least one known risk factor for IPD. The most common comorbid conditions were chronic kidney disease $(n=37)$, cardiovascular disease $(n=31)$, malignant disease $(n=31)$, diabetes $(n=27)$, and chronic liver disease $(n=20)$. Other risk factors for pneumococcal disease such as skull fracture $(n=18)$ and immunosuppressive treatment $(\mathrm{n}=32)$ were also present. Pneumonia $(\mathrm{n}=102)$ was the most common clinical manifestation, followed by meningitis $(n=58)$, septicemia without known focus $(\mathrm{n}=51)$, and peritonitis and arthritis $(n=21)$. Out of all patients, $216(88 \%)$ were treated as inpatients and $22(9 \%)$ were treated as outpatients (no data available for six patients, 3\%). The duration of admission ranged from 1-48 days, with a median of 6 days. Altogether, 49 patients (20\%) died during their hospital stay from causes related to the infection $(25 \%$ in $2007,18 \%$ in $2008,31 \%$ in $2009,18 \%$ in $2010,16 \%$ in 2011). 


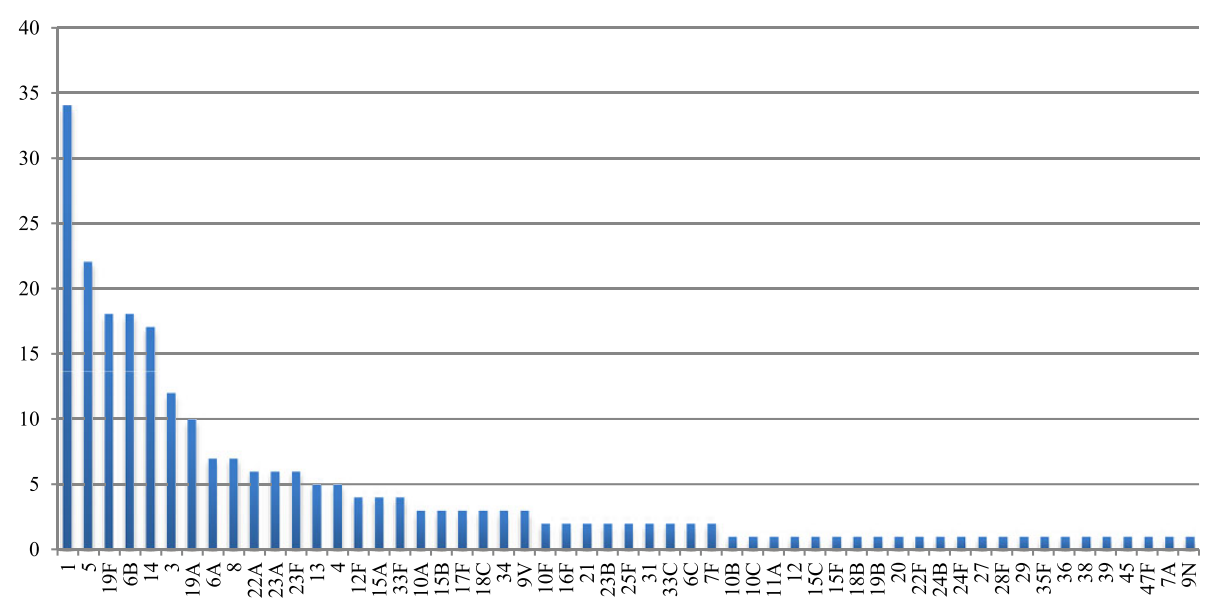

Figure 1 Serotype distribution of $S$ pneumoniae in samples collected between January 2007 and June 2011 at Christian Medical College and Hospital in Vellore, India ( $\mathrm{N}=244)$.

Figure 1 shows the serotype distribution among all isolates. One of the isolates in serogroup 12 was not serotyped. Case fatality rate, risk factors, and clinical manifestations among patients infected by the five most common serotypes are shown in Table 1, and the same parameters related to groups of serotypes are shown in Table 2. The age distribution and the potential vaccine coverage in different age groups are shown in Table 3.

Among adults, serotype 1 was more significantly associated with lower frequency of predisposing factors than other serotypes. It also caused more pneumonia and less meningitis than all other serotypes in adults. Among children, serotype 1 caused more pneumonia than other serotypes. No significant differences were found in case fatality rates.

When clustering the serotypes as "invasive" and "pediatric", some significant differences were observed (Table 2). "Invasive" serotypes were more often isolated from patients with no known risk factors for IPD than non- invasive serotypes. They were also more likely to cause pneumonia and less likely to cause meningitis. Children aged 0-1 were underrepresented in this group. The group of "pediatric" serotypes showed significantly lower ability to cause pneumonia and higher ability to cause meningitis than non-pediatric serotypes. This group was also significantly more prevalent in the $0-1$ year-old age

Table 1 Clinical characteristics of individual serotypes

\begin{tabular}{|c|c|c|c|c|c|c|c|c|c|}
\hline \multirow[t]{2}{*}{ Serotype } & \multirow{2}{*}{$\begin{array}{l}\text { All } \\
\qquad \text { No }\end{array}$} & \multicolumn{2}{|c|}{ Fatal outcome } & \multicolumn{2}{|c|}{ Any risk factor } & \multicolumn{2}{|l|}{ Pneumonia } & \multicolumn{2}{|l|}{ Meningitis } \\
\hline & & No (\%) & P-value & No (\%) & P-value & No (\%) & P-value & No (\%) & P-value \\
\hline & Children & $($ all = 95) & & $($ all = 95) & & $($ all = 93) & & $($ all = 93 $)$ & \\
\hline 1 & 10 & $0(0 \%)$ & ns & $2(22 \%)$ & ns & $7(88 \%)$ & 0.007 & $0(0 \%)$ & ns \\
\hline 5 & 6 & $0(0 \%)$ & ns & $0(0 \%)$ & ns (0.059) & $2(40 \%)$ & ns & $3(60 \%)$ & ns (0.084) \\
\hline $19 F$ & 11 & $2(18 \%)$ & ns & $5(46 \%)$ & ns & $5(46 \%)$ & ns & $2(18 \%)$ & ns \\
\hline $6 B$ & 8 & $2(25 \%)$ & ns & $4(50 \%)$ & ns & $2(25 \%)$ & ns & $3(38 \%)$ & ns \\
\hline 14 & 14 & $0(0 \%)$ & ns & $5(36 \%)$ & ns & $4(31 \%)$ & ns & $3(23 \%)$ & ns \\
\hline All serotypes & & $12(13 \%)$ & & $44(46 \%)$ & & $38(41 \%)$ & & $22(24 \%)$ & \\
\hline & Adults & $(\mathrm{all}=138)$ & & $($ all $=138)$ & & $(\mathrm{all}=136)$ & & $($ all = 136) & \\
\hline 1 & 24 & $3(13.0 \%)$ & ns & $10(43.5 \%)$ & $<0.001$ & $20(87.0 \%)$ & $<0.001$ & $2(8.7 \%)$ & 0.038 \\
\hline 5 & 16 & $4(25.0 \%)$ & ns & 11 (68.8\%) & ns & $9(64.3 \%)$ & ns & $2(14.3 \%)$ & ns \\
\hline $19 F$ & 7 & $2(40.0 \%)$ & ns & $6(100 \%)$ & ns & $3(60.0 \%)$ & ns & $2(40.0 \%)$ & ns \\
\hline $6 B$ & 10 & $3(30.0 \%)$ & ns & 10 (100.0\%) & ns & $2(20.0 \%)$ & ns & $6(60.0 \%)$ & 0.022 \\
\hline 14 & 3 & 1 (33.3\%) & ns & $2(66.7 \%)$ & ns & $3(100.0 \%)$ & ns & $0(0 \%)$ & ns \\
\hline All serotypes & & 37 (26.8\%) & & 107 (77.5\%) & & 64 (47.1\%) & & $36(26.5 \%)$ & \\
\hline
\end{tabular}

Clinical characteristics of the five most common pneumococcal serotypes in children and adults. P-values were calculated for each serotype compared with all other serotypes, using Fisher's exact test (two-sided). ns = not significant. 
Table 2 Clinical characteristics of grouped serotypes

\begin{tabular}{|c|c|c|c|c|c|c|c|c|c|c|c|}
\hline \multirow[t]{3}{*}{ Serotype group } & \multirow[t]{2}{*}{ All patients } & \multicolumn{2}{|c|}{ Fatal outcome } & \multicolumn{2}{|c|}{ Any risk factor } & \multicolumn{2}{|l|}{ Pneumonia } & \multicolumn{2}{|l|}{ Meningitis } & \multicolumn{2}{|l|}{$<2$ years } \\
\hline & & $($ all $=233)$ & & $($ all = 233) & & (all = 229) & & $($ all = 229) & & $($ all $=244)$ & \\
\hline & No & $\mathrm{No}(\%)$ & P-value & $\mathrm{No}(\%)$ & P-value & $\mathrm{No}(\%)$ & P-value & $\mathrm{No}(\%)$ & P-value & $\mathrm{No}(\%)$ & P-value \\
\hline Invasive & 59 & $8(14 \%)$ & ns & $25(46.3 \%)$ & 0.002 & $40(75.5 \%)$ & $<0.001$ & $8(15 \%)$ & ns (0.07) & $5(9 \%)$ & ns (0.07) \\
\hline Pediatric & 91 & $20(23 \%)$ & ns & $53(60.2 \%)$ & ns & 30 (35.3\%) & 0.039 & $29(34 \%)$ & 0.03 & $26(29 \%)$ & $<0.001$ \\
\hline PCV10 & 128 & $23(19 \%)$ & ns & $68(55.7 \%)$ & 0.003 & 65 (54.6\%) & 0.001 & $28(24 \%)$ & ns & 27 (21\%) & ns \\
\hline PCV13 & 157 & $32(21 \%)$ & ns & 87 (58.0\%) & 0.004 & 76 (51.7\%) & 0.004 & $31(21 \%)$ & ns (0.06) & 29 (19\%) & ns \\
\hline All serotypes & 244 & 49 (21\%) & & $151(64.8 \%)$ & & $102(44.5 \%)$ & & $58(25 \%)$ & & $41(17 \%)$ & \\
\hline
\end{tabular}

Clinical characteristics related to pneumococcal serotypes clustered into "invasive", "pediatric", PCV10 and PCV13 serotypes, with each group compared with all other serotypes. P-values calculated with Fisher's exact test (two-sided).

group. Serotypes included in the PCV10 and PCV13 vaccines were more often isolated from patients without risk factors for IPD and more likely to cause pneumonia, when comparing to all other serotypes.

Susceptibility to antimicrobial agents is shown in Table 4. When testing the antibiotic susceptibility, 11 (4.5\%) of the isolates had reduced susceptible (intermediate or resistant, I or R) to penicillin. For erythromycin, 33 (13.6\%) were non-susceptible. In total, 13 (5.3\%) were MDR. The serotypes that included MDR isolates were $6 \mathrm{~B}$ (5 isolates), $19 \mathrm{~F}$ (2), 1 (1), 14 (1), 19A (1), $23 \mathrm{~F}(1), 3$ (1), and 6A (1). PCV13 covered all of the 13 MDR serotypes, while PCV10 covered 10 (77\%) of the MDR serotypes. Serotypes 3 and 8 were significantly associated with higher susceptibility to any of the antimicrobial agents tested, while PCV10 and PCV 13 serotypes were both significantly associated with lower susceptibility (I or R) to any antimicrobial agent tested. We also present results excluding cotrimoxazole because of its widespread resistance $(\mathrm{I}+\mathrm{R}=83 \%)$, see Table 5 .

\section{Discussion}

The most common serotypes in the present study were $1,5,19 \mathrm{~F}, 6 \mathrm{~B}, 14$, and 3 . This result is similar to a national Indian study from 1999, but with minor differences in order of prevalence, and a decreased prevalence of serogroup 7 [16]. A small study from the same area in

Table 3 Vaccine coverage

\begin{tabular}{|c|c|c|c|c|c|c|}
\hline & Vaccines & $<2$ yrs & 2-17 yrs & $18-59$ yrs & $\geq 60$ yrs & All ages \\
\hline & PCV7 & 23 (49\%) & $18(36 \%)$ & 19 (17.0\%) & $10(29 \%)$ & $70(28.7 \%)$ \\
\hline & PCV10 & $28(60 \%)$ & 29 (58\%) & $50(44.6 \%)$ & $21(60 \%)$ & $128(52.5 \%)$ \\
\hline & PCV13 & $32(68 \%)$ & 35 (70\%) & $63(56.2 \%)$ & 27 (77\%) & 157 (64.3\%) \\
\hline & PCV15* & $33(70 \%)$ & 37 (74\%) & 64 (57.1\%) & $28(80 \%)$ & 162 (66.4\%) \\
\hline & PPV23** & $33(70 \%)$ & 41 (82\%) & 75 (67.0\%) & 29 (83\%) & 178 (73.0\%) \\
\hline Total & & 47 & 50 & 112 & 35 & 244 \\
\hline
\end{tabular}

Number (percent) of strains covered by $P C V-7,-10,-13$, the coming $P C V 15$ and the PPV23 in different age groups and all ages. $N=244{ }^{*} P C V 15$ includes all $P C V 13$ serotypes, $22 \mathrm{~F}$ and $33 \mathrm{~F}$. ${ }^{*}$ Pneumococcal polysaccharide vaccine 23 , includes serotypes $1,2,3,4,5,6 \mathrm{~B}, 7 \mathrm{~F}, 8,9 \mathrm{~N}, 9 \mathrm{~V}, 10 \mathrm{~A}, 11 \mathrm{~A}, 12 \mathrm{~F}, 14,15 \mathrm{~B}$, $17 \mathrm{~F}, 18 \mathrm{C}, 19 \mathrm{~A}, 19 \mathrm{~F}, 20,22 \mathrm{~F}, 23 \mathrm{~F}, 33 \mathrm{~F}$.
India showed similar results [17]. A study of serotypes in South-East Asia showed a similar ranking order to our study [18]. In that review, analyzing 3067 isolates from 23 studies, the ranking order was $19 \mathrm{~F}, 23 \mathrm{~F}, 14,6 \mathrm{~B}, 1$, and 3 . In contrast, there are major differences when comparing these studies to those conducted in high-income countries where serotypes $9 \mathrm{~V}, 4,7 \mathrm{~F}$ and $12 \mathrm{~F}$ are more common $[4,7]$. Longitudinal studies have shown that the incidence of serotype 1 varies over time, which might explain this observation $[19,20]$.

The proportion of serotypes identified in the current study that are included in the vaccines PCV7, 10, and 13 for all ages was $29 \%, 53 \%$, and $64 \%$, respectively, and $54 \%, 66 \%$, and $71 \%$, respectively, for children $<2$ years . The vaccine coverage was higher among children $<2$ years, the age group that will be most in need of PCV. The overall coverage seems to be slightly lower than in many high income countries. In Sweden, the coverage for PCV7 serotypes prior to the introduction of PCV7 in the national immunization program was $42 \%$ among all ages and $62 \%$ among children $0-4$ years of age [7]. When discussing this matter, one must consider the much higher prevalence of pneumococcal disease in India. Even if the vaccine coverage is lower than in other countries, the number of disease episodes and deaths that can be

Table 4 Susceptibilities of S. pneumoniae isolates to antimicrobial agents. I = intermediate, $R=$ resistant

\begin{tabular}{lll}
\hline & I & $\mathbf{R}$ \\
\hline Penicillin $(n=243)$ & $7(2.9 \%)$ & $4(1.6 \%)$ \\
Erythromycin $(n=243)$ & $6(2.5 \%)$ & $27(11.1 \%)$ \\
Chloramphenicol $(n=243)$ & $0(0 \%)$ & $4(1.6 \%)$ \\
Cotrimoxazole $(n=243)$ & $32(13.1 \%)$ & $181(74.2 \%)$ \\
Cefotaxime $(n=243)$ & $0(0 \%)$ & $1(0.4 \%)$ \\
Oxacillin $(n=193)$ & $3(1.2 \%)$ & $8(3.3 \%)$ \\
Levofloxacin $(n=182)$ & $3(1.2 \%)$ & $0(0 \%)$ \\
Linezolid $(n=203)$ & $0(0 \%)$ & $0(0 \%)$ \\
Vancomycin $(n=205)$ & $0(0 \%)$ & $0(0 \%)$ \\
\hline Multidrug resistant $(n=242)$ & & $13(5.3 \%)$ \\
\hline
\end{tabular}


Table 5 Susceptibilities of individual serotypes and grouped serotypes

\begin{tabular}{|c|c|c|c|c|c|c|}
\hline \multirow[b]{2}{*}{ Serotype } & \multirow[b]{2}{*}{ No. of strains } & \multirow[b]{2}{*}{ Missing } & \multicolumn{2}{|c|}{ All antibiotics* } & \multicolumn{2}{|c|}{ Without cotrimoxazole } \\
\hline & & & I/R & P-value & $\mathrm{I} / \mathrm{R}$ & P-value \\
\hline 1 & 34 & 8 & $25(96.2 \%)$ & ns & $2(7.7 \%)$ & ns \\
\hline 5 & 22 & 6 & $16(100 \%)$ & ns & $1(6.2 \%)$ & ns \\
\hline $19 F$ & 18 & 6 & $12(100 \%)$ & ns & $6(50 \%)$ & 0.011 \\
\hline $6 B$ & 18 & 5 & $13(100 \%)$ & ns & $5(38.5 \%)$ & ns (0.069) \\
\hline 14 & 17 & 10 & 7 (100\%) & ns & $3(42.9 \%)$ & ns \\
\hline 3 & 12 & 3 & $3(33.3 \%)$ & $<0.001$ & $1(11.1 \%)$ & ns \\
\hline $19 A$ & 10 & 2 & $8(100 \%)$ & ns & $3(37.5 \%)$ & ns \\
\hline $6 \mathrm{~A}$ & 7 & 4 & $3(100 \%)$ & ns & $2(66.7 \%)$ & ns (0.089) \\
\hline 8 & 7 & 0 & $1(14.3 \%)$ & $<0.001$ & $0(0 \%)$ & ns \\
\hline PCV10 types & 128 & 41 & $85(97.7 \%)$ & $<0.001$ & $19(21.8 \%)$ & ns \\
\hline PCV13 types & 157 & 50 & 99 (92.5\%) & 0.021 & 25 (23.4\%) & 0.033 \\
\hline Total & 244 & 83 & $142(88.2 \%)$ & & $30(18.6 \%)$ & \\
\hline
\end{tabular}

Reduced susceptibility of serotypes to any of the antimicrobial agents tested, calculated both including and excluding cotrimoxazole. Each serotype/group was compared with all other serotypes. ns = not significant *Penicillin, erythromycin, chloramphenicol, cefotaxime, oxacillin, levofloxacin, linezolid, vancomycin.

prevented with vaccination is substantial. However, because the percentages of isolates that are covered by the common conjugate vaccines are lower than they were in the U.S. prior to general vaccination, some of the herd effects that were observed in the U.S. might not occur to the same extent if general vaccination with PCV10 or PCV13 was started in India [21]. On the other hand, herd effects were observed in Europe despite a 15-20\% lower coverage [22]. It is difficult to predict the rate of serotype replacement, which depends on several factors, such as the proportion of non-vaccine serotypes prior to vaccination, serotype coverage of the vaccine, and overcrowded living conditions.

When analyzing the properties of individual serotypes, clinically relevant findings were made. In adults, serotype 1 tended to infect patients without any known risk factor for IPD, and caused more pneumonia and less meningitis than other serotypes. This is consistent with other studies $[5,7,23]$. In children, less significant values were found. This can be explained by a lower number of isolates, but also highlights the fact that serotypes behave differently in children and adults. Only a few correlations were found when analyzing other individual serotypes, which is probably explained by too few isolates of each serotype. Analysis of the properties of individual serotypes should be interpreted carefully, as confounding factors might be present.

It should be noted that the properties of pneumococci are not only dependent on serotype. Genotypic differences within and between different serotypes are also highly important, and were not investigated in this study. It is noteworthy that serotype 1 infections in West Africa seem to have a completely different pattern, with high case fatality rates and a larger proportion of meningitis [24,25]. This might be explained by the fact that other clones of serotype 1 dominate in West Africa, as compared to Europe [26]. Although we did not perform any clonal analysis in this study, it is likely that isolates of serotype 1 from this study belong to the same clones that are found in Europe, because the clinical characteristics are very similar. Further studies of the clonality of Indian IPD isolates are needed.

When the serotypes were clustered, the group of "invasive" serotypes differed significantly from other serotypes, in similar manner to a previous Swedish study [6]. They tended to infect patients without any known risk factors for IPD, caused more pneumonia and less meningitis, and were also less common among children $<2$ years of age. The group of "pediatric" serotypes also differed from other serotypes in terms of manifestation and age distribution. An international study, analyzing 796 isolates from adults from 10 countries, showed that host factors are of more importance than serotype when it comes to severity and outcome of pneumococcal disease [4]. Our present study showed no significant differences in case fatality rate between individual serotypes or when grouping them.

Only a small proportion of the isolates $(n=11,4.9 \%)$ had reduced susceptibility to penicillin, and resistance to other antimicrobial substances was also low (except for cotrimoxazole). This is consistent with The Asian Network for Surveillance of Resistant Pathogens (ANSORP) data showing that India has the lowest incidence of penicillinresistant S. pneumoniae in Asia [27]. Serotypes 3 and 8 were significantly associated with higher antimicrobial susceptibility than other serotypes. Also, serotypes included in PCV10 and PCV13 were significantly associated with higher antimicrobial resistance. All MDR isolates belonged 
to PCV-13 serotypes, whereas only $77 \%$ belonged to PCV-10 serotypes. Theoretically, widespread childhood vaccination with a vaccine protecting against a larger proportion of serotypes, which are often seen together with resistance, could have a positive impact on overall resistance in pneumococci. Resistance seemed to have no impact on outcome, but the number of patients was too small to permit any conclusion.

The relatively small number of patients presenting with IPD over the time period studied is explained by the fact that most patients in this district are relatively poor and cannot afford expensive investigations such as bacterial culturing. Also, prior antibiotic treatment (over the counter) before culture collection results in less verified IPD.

The gender distribution in this population is worth highlighting; in our study, $69 \%$ of IPD patients were men. This could be explained by that men are more likely to seek health care in India. Also, men are more exposed to socio-economically related risk factors, such as alcohol, smoking and labor in a polluted environment.

Children less than 1 year of age, an age group that usually has the highest incidence of IPD, were underrepresented in this study. In this population, children are often treated presumptively without investigation, as the cost of clinical testing (such as microbiological cultivation) is not affordable.

There are some limitations to the current study. Clinical data were collected retrospectively from medical records, which do not always accurately reflect the clinical situation. For example, smoking is not always mentioned in medical records, but we had to assume that a patient was a non-smoker if it was not mentioned. Also, as CMC is a renowned referral hospital and medical treatment is often costly, the selection of cases may not be representative of the population. Finally, the number of individual serotypes is quite small and analysis for each serotype was not possible. Therefore, clustering of the serotypes was performed.

Invasive pneumococcal infection is a serious problem worldwide, and India has the highest total number of children who die from pneumococcal disease [15]. The introduction of a PCV into the Indian national immunization program has been a matter of discussion for several years [28]. A recent randomized study from India shows that PCV10 is immunogenic and well tolerated when coadministrated with $\mathrm{DTPw}-\mathrm{HBV} / \mathrm{HiB}$ in Indian children [29]. PCV13 has also been proven to be immunogenic in other parts of the world [30].

\section{Conclusions}

This study shows that serotype distribution in India remains stable. In addition, the distribution of pneumococcal serotypes and their clinical characteristics are similar to countries where the PCV has been introduced, which strengthens the hypothesis that introduction of a PCV in India might be as successful as it has been in high income countries. This study contributes to a further understanding of IPD in India, although more research is needed.

\section{Competing interests}

Erik Backhaus is a member of the advisory board for Pfizer, Sweden, and a speaker at meetings sponsored by Pfizer.

\section{Authors' contributions}

VM and CE designed the study, collected the data, performed the statistical analysis, and wrote the manuscript. VB supervised the study and related work in Vellore. EB participated in the design of the study and assisted with writing the manuscript. JJ, RV, and RJ performed the serotyping. RA supervised the study, participated in the study design, and helped write the manuscript. All authors read and approved the final manuscript.

\section{Acknowledgements}

We thank The World Health Organization (WHO) for funding the surveillance of pneumococcal serotypes in India. We also thank the Swedish International Development Cooperation Agency (SIDA) and The Sahlgrenska Academy at the University of Gothenburg for financial support, as well as the staff of the Department of Microbiology at Christian Medical College, Vellore, for collecting pneumococcal isolates. Finally, thanks to Dr Biju Roy (Department of Microbiology, Christian Medical College, Vellore) for valuable support and help.

\section{Author details}

${ }^{1}$ Institute of Biomedicine, Department of Infectious Diseases, Sahlgrenska Academy, University of Gothenburg, Guldhedsgatan 10 A, P.O. Box 7193, 40234, Gothenburg, Sweden. ${ }^{2}$ Department of Microbiology, Christian Medical College, CMC \& H, Ida Scudder Road Vellore-4, Vellore, India. ${ }^{3}$ Department of Infectious Diseases, Skaraborg Regional Hospital, S-541 85, Skövde, Sweden.

Received: 29 May 2013 Accepted: 7 November 2013

Published: 9 November 2013

\section{References}

1. Bravo LC: Overview of the disease burden of invasive pneumococcal disease in Asia. Vaccine 2009, 27:7282-7291.

2. Sjostrom K, Spindler C, Ortqvist A, Kalin M, Sandgren A, Kuhlmann-Berenzon S, Henriques-Normark B: Clonal and capsular types decide whether pneumococci will act as a primary or opportunistic pathogen. Clin Infect Dis 2006, 42:451-459.

3. Brachman PS, Abrutyn E: Bacterial infections of humans: epidemiology and control. New York: Springer Science + Business Media; 2009.

4. Alanee SR, McGee L, Jackson D, Chiou CC, Feldman C, Morris AJ, Ortqvist A, Rello J, Luna CM, Baddour LM, Ip M, Yu VL, Klugman KP: Association of serotypes of Streptococcus pneumoniae with disease severity and outcome in adults: an international study. Clin Infect Dis 2007, 45:46-51.

5. Jansen $A G$, Rodenburg GD, van der Ende $A$, van Alphen $L$, Veenhoven $R H$, Spanjaard L, Sanders EA, Hak E: Invasive pneumococcal disease among adults: associations among serotypes, disease characteristics, and outcome. Clin Infect Dis 2009, 49:e23-e29.

6. Trollfors B, Berg S, Backhaus E, Andersson R, Bossen Konradsen H: Invasive, paediatric, vaccine strains of Streptococcus pneumoniae: are there differences in clinical characteristics? Scand J Infect Dis 2009, 41:84-87.

7. Berg S, Trollfors B, Persson E, Backhaus E, Larsson P, Ek E, Claesson BE, Jonsson L, Radberg G, Johansson S, Ripa T, Kaltoft MS, Konradsen HB: Serotypes of Streptococcus pneumoniae isolated from blood and cerebrospinal fluid related to vaccine serotypes and to clinical characteristics. Scand J Infect Dis 2006, 38:427-432.

8. Skinner JM, Indrawati L, Cannon J, Blue J, Winters M, Macnair J, Pujar N, Manger W, Zhang Y, Antonello J, Shiver J, Caulfield M, Heinrichs JH: Pre-clinical evaluation of a 15-valent pneumococcal conjugate vaccine (PCV15-CRM197) in an infant-rhesus monkey immunogenicity model. Vaccine 2011, 29:8870-8876.

9. Myint TT, Madhava H, Balmer P, Christopoulou D, Attal S, Menegas D, Sprenger R, Bonnet $\mathrm{E}$ : The impact of 7-valent pneumococcal conjugate 
vaccine on invasive pneumococcal disease: a literature review. Adv Ther 2013, 30:127-151.

10. Munoz-Almagro C, Esteva C, de Sevilla MF, Selva L, Gene A, Pallares R: Emergence of invasive pneumococcal disease caused by multidrug-resistant serotype 19A among children in Barcelona. J Infect 2009, 59:75-82.

11. Lalitha MK, Pai R, John TJ, Thomas K, Jesudason MV, Brahmadathan KN, Sridharan G, Steinhoff MC: Serotyping of Streptococcus pneumoniae by agglutination assays: a cost-effective technique for developing countries. Bull World Health Organ 1996, 74:387-390.

12. Pai $R$, Gertz RE, Beall B: Sequential multiplex PCR approach for determining capsular serotypes of Streptococcus pneumoniae isolates. J Clin Microbiol 2006, 44:124-131.

13. CLSI: Methods for Dilution Antimicrobial Susceptibility Tests for Bacteria That Grow Aerobically; Approved Standard-Eighth Edition CLSI document M07-A8. Wayne, PA: Clinical and Laboratory Standards Institute; 2009.

14. CLSI: Performance Standards for Antimicrobial Susceptibility Testing; Twenty-First Informational Supplement. CLSI document M100-S21. Wayne, PA: Clinical and Laboratory Standards Institute; 2011.

15. O'Brien KL, Wolfson L, Watt JP, Henkle E, Deloria-Knoll M, McCall N, Lee E, Mulholland K, Levine OS, Cherian T: Burden of disease caused by Streptococcus pneumoniae in children younger than 5 years: global estimates. Lancet 2009, 374:893-902.

16. Prospective multicentre hospital surveillance of Streptococcus pneumoniae disease in India: Invasive Bacterial Infection Surveillance (IBIS) Group, International Clinical Epidemiology Network (INCLEN). Lancet 1999, 353:1216-1221.

17. John TJ, Pai R, Lalitha MK, Jesudason MV, Brahmadathan KN, Sridharan G, Steinhoff MC: Prevalence of pneumococcal serotypes in invasive diseases in southern India. Indian J Med Res 1996, 104:205-207.

18. Jauneikaite $\mathrm{E}$, Jefferies JM, Hibberd ML, Clarke SC: Prevalence of Streptococcus pneumoniae serotypes causing invasive and non-invasive disease in South East Asia: a review. Vaccine 2012, 30:3503-3514.

19. Harboe ZB, Benfield TL, Valentiner-Branth $P$, Hjuler T, Lambertsen L, Kaltoft M, Krogfelt K, Slotved HC, Christensen JJ, Konradsen HB: Temporal trends in invasive pneumococcal disease and pneumococcal serotypes over 7 decades. Clin Infect Dis 2010, 50:329-337.

20. Henriques Normark B, Kalin M, Ortqvist A, Akerlund T, Liljequist BO, Hedlund J, Svenson SB, Zhou J, Spratt BG, Normark S, Kallenius G: Dynamics of penicillin-susceptible clones in invasive pneumococcal disease. J Infect Dis 2001, 184:861-869.

21. Pilishvili T, Lexau C, Farley MM, Hadler J, Harrison LH, Bennett NM, Reingold A Thomas A, Schaffner W, Craig AS, Smith PJ, Beall BW, Whitney CG, Moore MR: Sustained reductions in invasive pneumococcal disease in the era of conjugate vaccine. J Infect Dis 2010, 201:32-41.

22. Miller E, Andrews NJ, Waight PA, Slack MP, George RC: Herd immunity and serotype replacement 4 years after seven-valent pneumococcal conjugate vaccination in England and Wales: an observational cohort study. Lancet Infect Dis 2011, 11:760-768.

23. Harboe ZB, Thomsen RW, Riis A, Valentiner-Branth P, Christensen JJ, Lambertsen L, Krogfelt KA, Konradsen HB, Benfield TL: Pneumococcal serotypes and mortality following invasive pneumococcal disease: a population-based cohort study. PLoS Med 2009, 6:e1000081.

24. Yaro S, Lourd M, Traore Y, Njanpop-Lafourcade BM, Sawadogo A, Sangare L, Hien A, Ouedraogo MS, Sanou O, Parent Du Chatelet I, Koeck JL, Gessner BD: Epidemiological and molecular characteristics of a highly lethal pneumococcal meningitis epidemic in Burkina Faso. Clin Infect Dis 2006, 43:693-700.

25. Leimkugel J, Adams Forgor A, Gagneux S, Pfluger V, Flierl C, Awine E, Naegeli M, Dangy JP, Smith T, Hodgson A, Pluschke G: An outbreak of serotype 1 Streptococcus pneumoniae meningitis in northern Ghana with features that are characteristic of Neisseria meningitidis meningitis epidemics. J Infect Dis 2005, 192:192-199.

26. Antonio M, Hakeem I, Awine T, Secka O, Sankareh K, Nsekpong D, Lahai G, Akisanya A, Egere U, Enwere G, Zaman SM, Hill PC, Corrah T, Cutts F, Greenwood BM, Adegbola RA: Seasonality and outbreak of a predominant Streptococcus pneumoniae serotype 1 clone from The Gambia: expansion of ST217 hypervirulent clonal complex in West Africa. BMC Microbiol 2008, 8:198.

27. Song JH, Jung SI, Ko KS, Kim NY, Son JS, Chang HH, Ki HK, Oh WS, Suh JY, Peck KR, Lee NY, Yang Y, Lu Q, Chongthaleong A, Chiu CH, Lalitha MK,
Perera J, Yee T, Kumarasinghe G, Jamal F, Kamarulzaman A, Parasakthi N, Van PH, Carlos C, So T, Ng TK, Shibl A: High prevalence of antimicrobial resistance among clinical Streptococcus pneumoniae isolates in Asia (an ANSORP study). Antimicrob Agents Chemother 2004, 48:2101-2107.

28. Levine OS, Cherian T: Pneumococcal vaccination for Indian children. Indian Pediatr 2007, 44:491-496.

29. Lalwani S, Chatterjee S, Chhatwal J, Verghese VP, Mehta S, Shafi F, Borys D, Moreira M, Schuerman L: Immunogenicity, safety, and reactogenicity of the 10-valent pneumococcal non-typeable Hemophilus influenzae protein $\mathrm{D}$ conjugate vaccine (PHiD-CV) when co-administered with the DTPW-HBV/Hib vaccine in Indian infants: a single-blind, randomized, controlled study. Human vaccines \& immunotherapeutics 2012, 8:612-622.

30. Vanderkooi OG, Scheifele DW, Girgenti D, Halperin SA, Patterson SD, Gruber WC, Emini EA, Scott DA, Kellner JD: Safety and immunogenicity of a 13-valent pneumococcal conjugate vaccine in healthy infants and toddlers given with routine pediatric vaccinations in Canada. Pediatr Infect Dis J 2012, 31:72-77.

doi:10.1186/1471-2334-13-532

Cite this article as: Molander et al.: Invasive pneumococcal infections in Vellore, India: clinical characteristics and distribution of serotypes. BMC Infectious Diseases 2013 13:532.

\section{Submit your next manuscript to BioMed Central and take full advantage of:}

- Convenient online submission

- Thorough peer review

- No space constraints or color figure charges

- Immediate publication on acceptance

- Inclusion in PubMed, CAS, Scopus and Google Scholar

- Research which is freely available for redistribution

Submit your manuscript at www.biomedcentral.com/submit
C) Biomed Central 